\title{
Meio ambiente e espaço urbano: o projeto de revitalização do rio Maranguapinho, e seus impactos no Bairro Henrique Jorge, em Fortaleza-CE
}

Environment and urban space: the revitalization project Maranguapinho river, and its impact in the neighborhood Henrique Jorge, in Fortaleza-CE

\author{
Menezes $^{1}$, K. W.S. de; Sousa ${ }^{2}$, E. L. de; Castro ${ }^{3}$, F. F. B. de; Zanette ${ }^{4}$, F. R; Grangeiro ${ }^{5}$, C. M. M. \\ karinnewendy@gmail.com;
}

\begin{abstract}
Resumo
O presente trabalho tem a finalidade de fazer uma discussão sobre as questões ambientais e o processo de produção do espaço, a partir da análise do projeto de revitalização do rio Maranguapinho. Para tanto, foi realizado um estudo teórico acerca da temática abordada e visitas de campo, na comunidade e em órgãos públicos, a fim de melhor compreender a realidade do objeto em estudo. Deste modo, buscou-se compreender a redefinição do espaço urbano promovido pelo projeto no bairro Henrique Jorge, que se localiza na cidade de FortalezaCE. O rio Maranguapinho é um rio urbano, que está localizado na Região Metropolitana de Fortaleza, no estado do Ceará, em seu extenso percurso este rio passa por áreas desprivilegiadas da cidade, com grandes problemáticas socioambientais, como as constatadas no bairro Henrique Jorge.
\end{abstract}

Palavras-chave: meio ambiente, espaço urbano, rio Maranguapinho.

\begin{abstract}
The present work it aims to make a discussion of environmental issues and the space production process, from the analysis of the Maranguapinho river revitalization project. Thus, a theoretical study was carried out at about the selected theme and field visits, community and public agencies in order to better understand the reality of the object under study. We sought to understand the redefinition of urban space promoted by the project in Henrique Jorge neighborhood, which is located in the city of Fortaleza-CE. The river Maranguapinho is an urban river, which is located in the metropolitan area of Fortaleza, in Ceará state, in its extensive route, the river passes through underprivileged areas of the city with great social and environmental problems, as noted in neighborhood Henrique Jorge.
\end{abstract}

Keywords: environment, urban space, Maranguapinho river.

\section{INTRODUÇÃ̂O}

Esta pesquisa trata-se de uma breve análise do projeto de revitalização do rio Maranguapinho, com enfoque no bairro Henrique Jorge. Localizado na Região Metropolitana de Fortaleza, no estado do Ceará, com a sua nascente na serra de Maranguape-CE e desembocadura no rio Ceará, o Maraguapinho caracteriza-se como um rio urbano.

O Bairro Henrique Jorge está situado no setor oeste da cidade de Fortaleza-Ceará, de acordo com Almeida (2010), na ocupação urbana na zona oeste, prepondera os assentamentos

${ }^{1}$ Karinne Wendy Santos de Menezes, Mestranda do Programa de Pós-Graduação em Geografia, Universidade Estadual do Ceará UECE, Fortaleza-CE, Brasil.

${ }^{2}$ Emilio Lopes de Sousa, Graduando em Geografia, Universidade Estadual do Ceará - UECE, Fortaleza-CE, Brasil.

${ }^{3}$ Francisca Fernanda Batista de Castro, Mestranda do Programa de Pós-Graduação em Geografia, Universidade Estadual do Ceará - UECE, Fortaleza-CE, Brasil.

${ }^{4}$ Felipe Rabaioli Zanette, Mestrando do Programa de Pós-Graduação em Geografia, Universidade Federal do Rio Grande do Sul UFRGS, Porto Alegre-RS,Brasil. 
informais, infraestrutura precária e déficits na acessibilidade aos serviços de equipamentos urbanos, como transporte, saúde, educação, segurança, lazer e acesso a moradias.

No presente trabalho é analisado o trecho do bairro Henrique Jorge que fica compreendido na Avenida Porto Velho e a rua Boa Vista e faz fronteira com o bairro Genibaú, que apresenta grandes conflitos com essas comunidades.

As características socioespaciais da área apresentam-se como reflexo das relações sociais históricas do processo de ocupação deste setor da cidade, que revela relatos da década de 1940, mas a ocupação se intensifica na década de 1960 com o surgimento de moradias localizadas nas áreas de risco, em virtude da escassez do solo urbano.

A figura 01 traz a localização geográfica do bairro Henrique Jorge, em Fortaleza-CE.

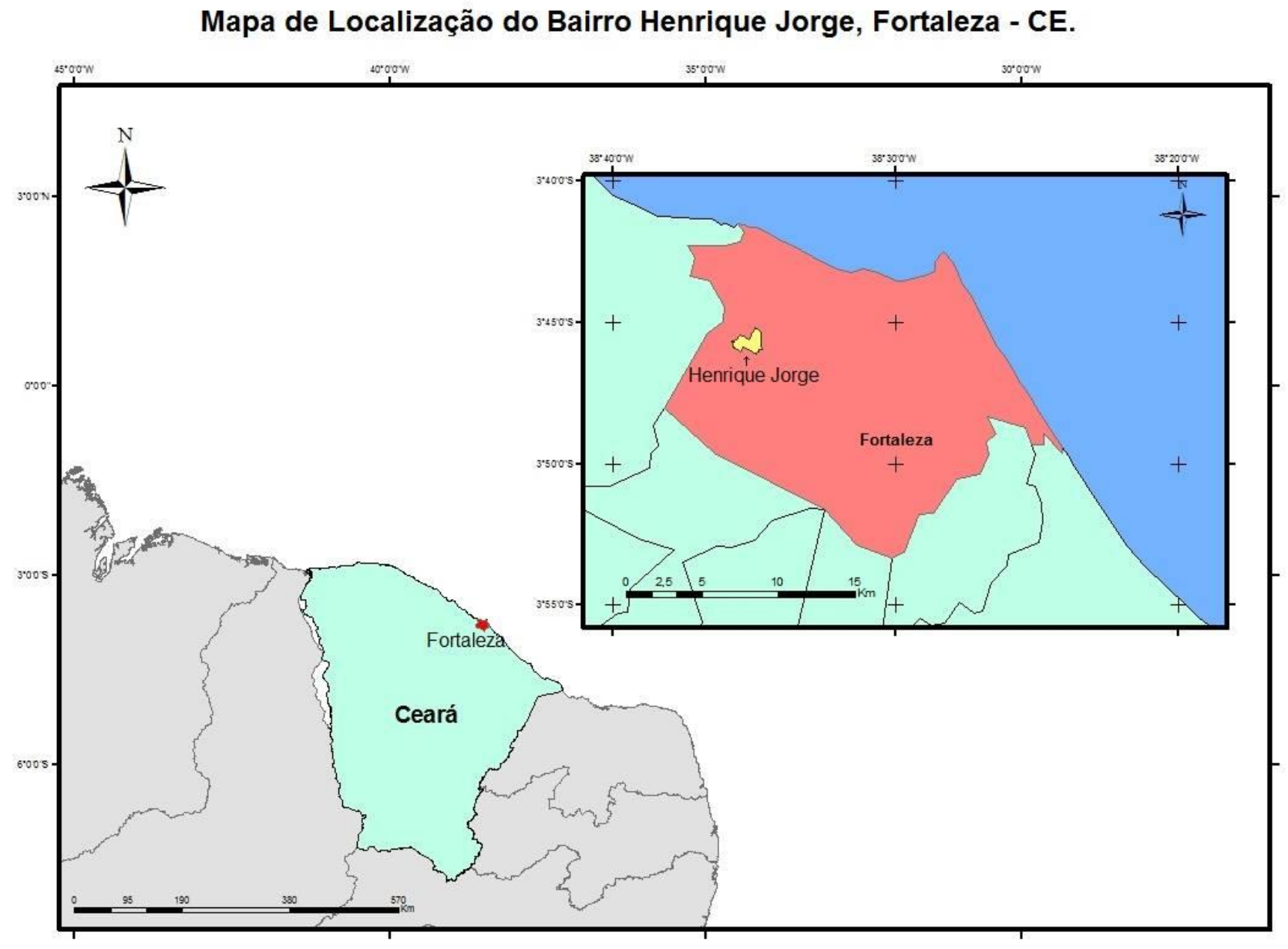

Figura 01: localização do bairro Henrique Jorge, em Fortaleza-Ce. Fonte: Zanette (2016).

Deste modo, o presente estudo foi elaborado com a finalidade de compreender o projeto de revitalização do rio Maranguapinho, e seus impactos sociais e ambientais no bairro Henrique Jorge, destacando a redefinição do espaço urbano promovido pelo projeto, a partir do processo de uso e ocupação, da área de planície fluvial do rio Maranguapinho, especificamente no trecho 
situado no bairro supracitado, sob a perspectiva de que a ocupação dessa planície se articula à dinâmica segregatória decorrente da lógica de urbanização desigual impressa na cidade.

O Projeto de Revitalização do Rio Maranguapinho está sob responsabilidade da Secretaria das Cidades do Estado do Ceará, entre seus principais objetivos, está a limpeza do Rio, o reassentamento das famílias que foram desapropriadas, que deverão ser devidamente indenizadas.

Segundo a Superintendência de Obras Hidráulicas do Estado (2015), o projeto de revitalização do Rio é um dos empreendimentos mais importantes do Programa de Aceleração do Crescimento (PAC), do Governo Federal, e está dividido em cinco grandes ações: dragagem, urbanização, habitação, barragem e esgotamento sanitário.

\section{METODOLOGIA}

Os procedimentos teóricos e metodológicos foram organizados em duas etapas complementares: a primeira correspondeu ao levantamento bibliográfico e pesquisa documental, como trabalhos acadêmicos e documentos sobre o Projeto de Revitalização do rio Maranguapinho; a segunda etapa refere-se aos trabalhos em campo realizados na Secretaria das Cidades e no Bairro Henrique Jorge, em Fortaleza-CE.

$\mathrm{Na}$ pesquisa utilizou-se bibliografia tanto sobre o objeto de estudo quanto sobre o processo ocupação da parte oeste da cidade de Fortaleza, assim como fragmentos de relatos sobre a sobre os processos de remoção propostos pela prefeitura.

Os trabalhos de campo foram realizados entre os anos de 2013-2014. No primeiro trabalho de campo foi realizada uma visita à Secretaria das Cidades, localizada em Fortaleza, para buscar informações sobre a elaboração e execução do Projeto de Revitalização do Rio Maranguapinho.

$\mathrm{Na}$ comunidade localizada entre a Avenida Porto Velho e a rua Boa Vista no bairro Henrique Jorge, foi realizado um campo para compreender o processo de remoção que atingia a comunidade. Foram realizadas entrevistas informais no intuito de se obter informações sobre o processo de ocupação e desapropriação da área.

\section{RESULTADOS E DISCUSSÃO}

O setor oeste da cidade de Fortaleza caracteriza-se por abrigar uma grande quantidade da população de baixa renda, com autos índices de pobreza e consequentemente uma ampla quantidade de moradias construída em áreas com grande vulnerabilidade ambiental às intervenções humanas. Somam-se a isso altos índices de violência, precariedade no atendimento à saúde e saneamento básico quase inexistente. 
A intensificação no povoamento do setor oeste da cidade de Fortaleza está relacionada ao alto índice de êxodo rural no estado do Ceará, que se apresenta como reflexo das condições de vida precária no campo e de uma estrutura fundiária desigual do meio agrário. Esse processo foi intensificado pela mudança que passou a estrutura produtiva brasileira em geral, e a da Região Metropolitana de Fortaleza em particular, que teve na indústria sua principal forma de reprodução. Normalmente localizada nos grandes centros, a mesma tem forte poder de atração da população. Industrialização e urbanização foram processos concomitantes e indissociáveis, tornando o inchaço urbano uma característica das cidades brasileiras que passaram por esse processo.

Nesse sentido, Almeida (2010) afirma que:

\begin{abstract}
A industrialização polarizada nas principais capitais do Nordeste - Recife, Salvador e Fortaleza - e as mudanças na estrutura produtiva e no padrão fundiário no campo, promoveram o aumento das disparidades intrarregionais e entre cidade-campo. Esse processo corroborou para o inchaço das metrópoles regionais em virtude da intensificação das correntes migratórias. (ALMEIDA, 2010, p. 123)
\end{abstract}

Grande parte dos migrantes do campo cearense foram excluídos do mercado fundiário "formal" e "regular", devido à valorização rápida do solo urbano e por não possuírem reservas financeiras necessárias para obtê-las.

Deste modo, as áreas de periferias e as margens do rio foram sendo cada vez mais ocupadas, sem um devido acompanhamento por parte do Estado. Isso nos leva a crer que o surgimento de áreas de risco equivale a um conjunto de ações históricas, decorrente de diferentes setores da sociedade que não são uma demanda solvável e têm na ocupação de tais áreas uma estratégia de sobrevivência. A contradição entre o solo urbano e a moradia como direito e condição fundamental para uma vida digna e a sua expressão em mercadoria marca uma realidade em grande parte dos centros urbanos brasileiros.

Fortaleza não foge à regra das cidades brasileiras. Constitui-se como uma cidade multifacetada, desigual e fragmentada, ainda que articulada. É uma verdadeira arena de interesses, onde atores diversos agentes buscam implantar suas estratégias e realizar suas ambições.

Concordamos com a classificação de Corrêa (1995) para a análise do espaço urbano. O autor identifica como agentes produtores do espaço urbano: os proprietários dos meios de produção, os proprietários fundiários, promotores imobiliários, o Estado e os grupos sociais excluídos. Os três primeiros agentes têm em comum a preocupação com a maximização da renda da terra, mesmo que possam ocorrer certas tensões entre eles. O Estado se reveste, à princípio, de certa autonomia e legitimidade, já que age em direção ao "bem-comum”. Entretanto longe de ser neutra, a ação do Estado é sempre parcial quando integrada no âmbito geral da cidade. Já os grupos sociais excluídos 
agem sobre o espaço pela força do espaço enquanto valor-de-uso e integrados em suas estratégias de sobrevivência e reprodução social.

$\mathrm{Na}$ área de estudo os atores envolvidos no processo de revitalização do rio Maraguapinho são elementos fundamentais e suas ações devem ser melhor compreendidas. Grande parte da população que mora na área, ali chegou por volta da década de 1980. Alguns saíram de outras partes da cidade, mas a grande maioria de municípios do interior do estado. Interessante notar que na área estudada foi estabelecida uma ocupação de famílias organizadas em uma associação que posteriormente foi dissolvida por motivos desconhecidos.

As ocupações, como já ditas anteriormente, irão ocorrer em cortiços e habitações precárias áreas desvalorizadas e, principalmente, fora do mercado regular de terras, onde grande parte delas está em áreas de risco, como aquelas situadas nas planícies de inundação de rios ou aquelas áreas com alta declividade e perigosamente propensas à movimentos de massa em encostas íngremes. Essa é a lógica espacial dos "grupos sociais excluídos” proposta por (Corrêa 1995).

As áreas de riscos ocupadas situadas na cidade desvalorizam em certa medida o solo urbano, logo surge à necessidade de intervenção, seja no processo de revitalização ou mesmo na criação de vias no local destas comunidades para melhor articular os fluxos no meio urbano. No caso estudado, a revitalização está intimamente ligada ao discurso ambiental pregando a necessidade de remoção das famílias por causa das enchentes periódicas do local.

As inundações na planície do rio Maranguapinho podem ser explicadas por determinados elementos da organização do espaço, que ao serem analisados conforme Almeida, (2010) revelam que:

\footnotetext{
O problema das inundações no âmbito da bacia hidrográfica do rio Maranguapinho é algo complexo e diz respeito além da problemática social e econômica da ocupação irregular por moradias pobres e ambientalmente inadequadas das margens do rio Maranguapinho e de seus afluentes, também abrangendo a estrutura urbanística presente em toda a bacia, que prima pelo asfalto, pelo concreto, pela intensa dispersão do tecido urbano e do padrão cartesiano das ruas e avenidas, que de longe consideram as características gerais do sítio urbano de Fortaleza. (ALMEIDA, 2010, p. 155)
}

No entanto, um número significativo de moradias da área removida nunca sofreu com enchentes do rio, contudo este foi o principal argumento utilizado pela secretaria das cidades para legitimar o processo de remoção destas famílias. O processo de avaliação das casas foi realizado por uma empresa privada, demonstrando o nível do processo de terceirização que o Estado vem sofrendo. Os valores apresentados nos relatórios ficaram muito abaixo do valor de mercado, como é praxe desse tipo de experiências em diversas cidades do Brasil.

No processo de negociação, os moradores relataram nas entrevistas que havia uma pressão por parte dos funcionários da secretaria das cidades, para que eles se retirarem de sua 
residência, por valores que não atendiam as suas necessidades de moradia. Isso permite evidenciar que a ação do Estado no espaço urbano não é neutra. Seja pelo papel do próprio ordenamento jurídico criado ou por sua ação direta, o Estado se torna auxiliar nas estratégias de outros agentes em se apropriar da renda da terra, agora aumentada pela "valorização" do espaço urbano afetado pela revitalização.

$\mathrm{Na}$ figura 02 pode-se visualizar o lançamento de materiais poluentes no rio Maranguapinho, no trecho que percorre o bairro Henrique Jorge.

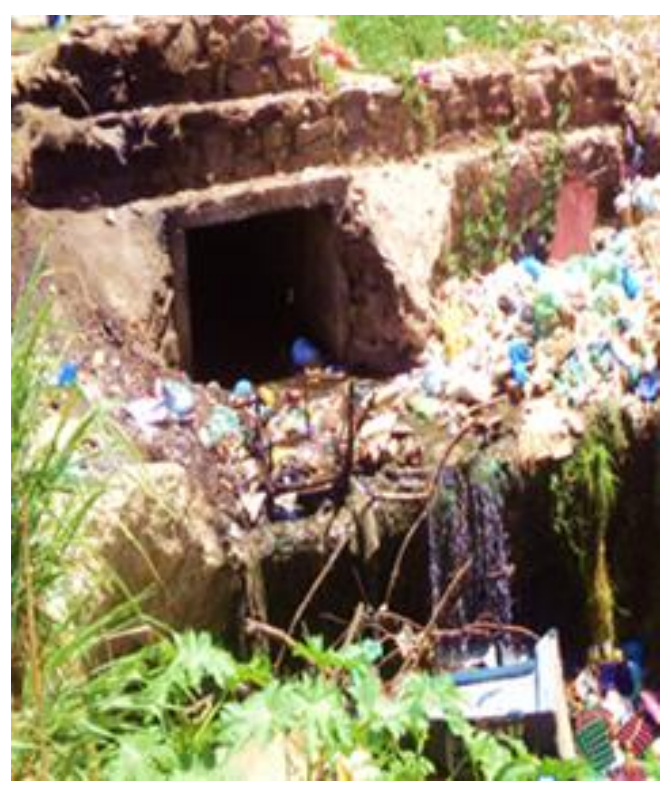

Figura 02: Poluentes no rio Maranguapinho, Henrique Jorge, Fortaleza-CE. Fonte: Menezes (2012).

O processo de intervenção nas áreas de riscos apresenta, assim, contradições, seja na identificação de grandes empreendimentos no local ou mesmo no processo de remoção das comunidades, em que os moradores construíram laços afetivos com o lugar. Além do que o processo de negociação é repleto de tensões, seja pelo valor oferecido pelo Estado ou mesmo pelo realojamento destas famílias em áreas distantes dos seus locais de trabalho e de estudo. A figura 03 mostra um dos residenciais construídos para realojar as famílias.

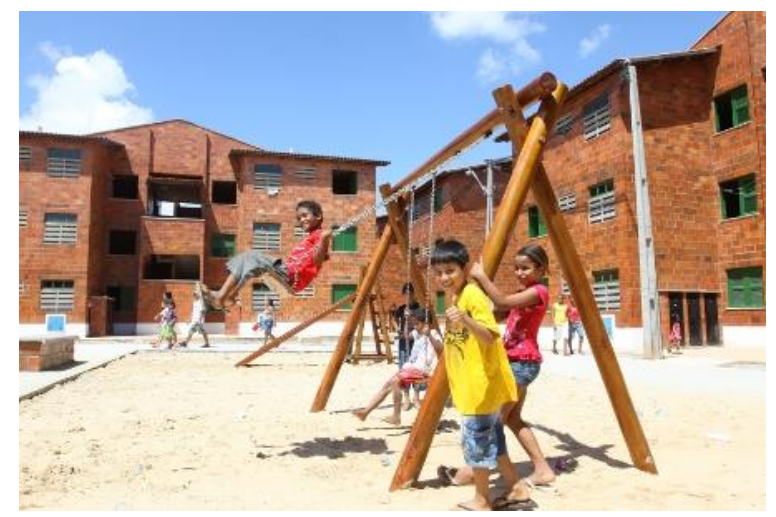

Figura 03: Residencial Rachel de Queiroz. Fonte: http://www.pge.ce.gov.br/ 
A existência desses conflitos ocorre na medida em que há diferentes agentes produtores do espaço urbano com interesses diversos. No fim e ao cabo, o espaço urbano é refém da contradição há muito conhecida: o solo urbano como "valor de uso" e como "valor de troca". A escolha do espaço como moradia e o desejo de transformá-lo em um grande empreendimento e o espaço como lugar de apropriação simbólica e produtor de significados afetivos são racionalidades muitas vezes opostas e incompatíveis. No processo ora em curso o Estado não se apresenta como simples mediador desses conflitos, mas como agente com forte influencia no processo de redefinição destes espaços.

\section{CONSIDERAÇÕES FINAIS}

Esse trabalho teve por objetivo realizar uma reflexão sobre o projeto de revitalização do rio Maranguapinho e a consequente redefinição do espaço urbano, no bairro Jorge Henrique, em Fortaleza-CE. Buscamos resgatar os agentes do espaço urbano e suas lógicas de ação, assim como a expressão espacial dos grupos sociais excluídos na cidade.

Nesse sentido, a preservação do ambiente e a melhoria da qualidade de vida de todas as pessoas da cidade não podem estar separadas da discussão urbana como um todo. Seja pelas características das cidades brasileiras e seu inchaço, ou pela quase inevitabilidade de determinados grupos que são tidos como uma "demanda insolvável" para o mercado regular de terras se apropriarem de áreas de risco para sua reprodução social.

O Estado, no caso estudado, se mostrou um agente propenso a reproduzir e ainda ampliar a lógica segregacionista e desigual do espaço urbano. Os baixos valores dados de indenização para as famílias às obrigam a mudar para lugares distantes, onde estão situadas as habitações populares da prefeitura. A terra enquanto mercadoria é, assim, o principal ponto de exclusão e segregação da cidade. Sem combater essa lógica fica difícil pensar em cidades diferentes e que proporcionem melhores condições de vida para todos seus habitantes.

\section{REFERÊNCIAS}

ALMEIDA, L. Q. de. Vulnerabilidades Socioambientais de Rios Urbanos: Bacia Hidrográfica do Rio Maranguapinho, Região Metropolitana de Fortaleza, Ceará. Tese de doutorado apresentado ao Instituto de Geociências e Ciências Exatas da Universidade Estadual Paulista, 2010. 278 p.

ALMEIDA, L. Q. de; CARVALHO, P. F. Representações, riscos e potencialidades de rios urbanos: análise de um (des) caso histórico. Revista Caminhos de Geografia. n. 34, v. 11, Uberlândia, 2010.

AMORA, Z. B. O Espaço urbano cearense: breves considerações. In: AMORA, Z. B. (organizadora). O Ceará: enfoques geográficos. Fortaleza, Editora: FUNECE, 1999. 143p. 
BERNARDES, J. A. e FERREIRA, Fco P. de M. Sociedade e Natureza. In: CUNHA, S. B. e GUERRA, A. J. T. (orgs) - A Questão Ambiental: diferentes abordagens. Rio de Janeiro: Bertrand Brasil, 2003. 248 p.

CARLOS, A. F. A (Re) Produção do Espaço Urbano. 1. Ed. 1. Reimpr. São Paulo: Editora da Universidade de São Paulo, 2008. 272 p.

CEARÁ, Procuradoria-Geral do Estado. Rio Maranguapinho. Disponível em: http://www.pge.ce.gov.br/site/sala-de-imprensa/noticias/1195-rio-maranguapinho-324-familiasrecebem-novas-moradias. Acesso em: 30/05/2014.

CEARÁ. Prefeitura de Fortaleza. Rio Maranguapinho. Disponível em: http://www.fortaleza.ce.gov.br/ ompdec/noticias/defesa-civil/prefeitura-limpa-bacias-domaranguapinho-e-lagoa-seca. Acesso em 30/05/2014.

CEARÁ. Superintendência de Obras Hidráulicas. Projeto de Urbanização do Rio Maraguapinho. Disponível em: http://www.sohidra.ce.gov.br/index.php/noticias/48002-projeto-de-urbanizacao-dorio-maranguapinho. Acesso em: 23 de maio 2016.

CORRÊA, R. L. O espaço urbano. São Paulo: Ática, 1995. 94 p.

GRANGEIRO, C. M. M. Meio ambiente litorâneo e urbanização: o ambiente produzido na costa leste da cidade de Fortaleza - Ceará. Tese de doutorado apresentada ao Programa de PósGraduação em Geografia da Universidade Estadual do Ceará, Fortaleza, 2012. 238 p.

HENRIQUE, W. O direito à natureza na cidade. Salvador: EDUFBA, 2009. 186 p.

SPÓSITO, M. E. B. Os embates entre as questões ambientais e sociais no urbano. In: CARLOS, A. F. A; LEMOS, A. I. G. (Org.) Dilemas urbanos: novas abordagens sobre a cidade. São Paulo: Contexto, 2005. 430 p.

SOUZA, M. J. N. de. Compartimentação geoambiental do Ceará. In. SILVA, J. B. da, CAVAlCANTE, T. C. e DANTAS, E.W. C. (org.) Ceará: um novo olhar geográfico. - 2. ed. Atual Fortaleza: edições Demócrito Rocha, 2007. 478 p.

\section{AGRADECIMENTOS}

À professora Claudia Maria Magalhães Grangeiro (In Memoriam), por todas as contribuições à nossa formação acadêmica e para o desenvolvimento deste trabalho;

Ao Programa de Educação Tutorial - PET Geografia da Universidade Estadual do Ceará e;

À Coordenação de Aperfeiçoamento de Pessoal de Nível Superior - Capes.

Recebido em: 14/08/2016

Aceito para publicação em: 01/10/2016 